\title{
Natural disasters in African countries: what can we learn about them?
}

\author{
MT LUKAMBA*
}

\begin{abstract}
Problems posed by disasters have become increasingly important for all African governments. Every year a variety of disasters occurs in Sub-Saharan Africa and these are becoming more prevalent. This article presents an analysis of statistical surveys for natural disasters in different regions of Africa over a 30-year period from 1974 to 2003 . It shows that disaster frequency is increasing on the continent. The investigation of the data demonstrates that the East Africa region is under the greatest threat from natural disasters. In 2008, climatological disasters, notably droughts, claimed many victims in the eastern part of Africa, with more than one third of the population affected in Djibouti, Eritrea, and Somalia. The region has experienced the highest recorded number of disaster events for the past 30 years, followed by the West Africa region. The Southern Africa region is placed third as far as the frequency of disaster events in sub-Saharan Africa is concerned. The least disaster prone region is central Africa. The observations made in this analysis relate to the economic losses in different regions from the impact of natural disasters. In some instances, recovery from economic loss could not be recouped because of stunted growth and other internal problems in these countries. In addition, this article suggests some strategies to mitigate the problem of natural hazards in sub-Saharan Africa.
\end{abstract}

Keywords Flood; drought; volcanic eruptions; political governance; climate change; specialised capabilities.

\section{Introduction}

Natural disasters occurring in African countries undermine the economic survival of poor communities. Many populations in countries throughout the continent have suffered under the impact of such hazards, which have killed thousands and caused injuries to many others. For example, the flood in Algeria in 2001 killed around 900 people and adversely affected approximately 45,000 others. In eastern Africa in 2002, heavy rain brought floods and mudslides that forced people to evacuate their homes in Tanzania, Uganda, Kenya, Burundi and Rwanda (Huq et al: 2007). Moreover, Homan (1996: 138) argues that contemporary research shows 
exposure to such disasters are far from "natural", and that power inequities may often explain differences in loss sustained and recovery time.

Perception studies reveal that people tend to view such events as an exaggeration of the natural world. Further, the UN-Habitat (2003) argues that developing nations, particularly those residents in major cities, face greater risk of economic and social catastrophes because of a relative lack of resources to adapt to the situation. This problem is exacerbated by the rapidly increasing urban population in most African countries.

Disasters create serious disruption and economic loss which impair the ability of communities (particularly the poorer people) to recover. Government assistance in such situations is often limited due to the already grave financial burdens they face. According to the International Strategy for Disaster Reduction (ISDR) (2004: 149), the African continent is exposed to disaster risk from various natural causes, particularly those arising from hydrometeorological hazards. One reason for this increase in disaster risk is the vulnerability of many communities; the risk to the livelihoods on which they depend, remains high. This vulnerability is also influenced by endemic poverty in many African countries, such as Malawi, Mozambique, and Zimbabwe. Another problem is recovery planning because not every national government is able to assist all poor communities. Furthermore, increased population growth in most African countries has become an additional problem. It is argued by Pelling and Wisner (2009) that the population of Sub-Saharan Africa is increasing, and that in 2007 it had risen to 800 million. The escalating urban population in African cities and towns poses a real challenge to managing disaster risk.

This article analyses 30 years of statistical data on natural disasters in Africa. It looks at various regions of the continent, and covers different types of hazards, such as floods, earthquakes, wildfires, drought and volcanoes. The 30 years (1974 to 2003) of statistical data focuses on different sub-regions of the African continent. In its analysis, the paper will also provide some suggestions on how to manage natural disasters in Africa.

\subsection{Methodology}

The researcher has used secondary statistical data covering 30 years of natural disasters on the African continent. This research is based on data gleaned from the Centre for Research on the Epidemiology of Disasters (CRED) at the University de Louvain in Belgium. Additional information has also been collected from various other international organisations including the World Bank, the United Nations' Children Fund (UNICEF), and the International Strategy for Disaster Reduction (ISDR). Other important documents and relevant statistics were found, inter alia, in the library at North-West University (Potchefstroom Campus).

Another point the paper highlights is that there are as yet very few scientific journals that publish information on disasters on the continent. Disaster risk management in Sub-Saharan Africa is still a relatively new field of study. This is one of the reasons why the paper makes use of many reports from international organisations that have collect data on different types of disaster occuring in Africa.

\section{Natural disasters in Sub-Saharan Africa}

It is obvious that with the increase of disaster risk in Africa, more people are adversely affected. Disaster events have substantially increased the economic loss of poor communities - so much so that the impact of disasters on the African continent has had a negative impact on sustainable 
development (Africa Union: 2006). The African Union claims that hydrometeorological hazards, such as floods, drought, windstorms, wildfire, and tropical cyclones have accounted for loss of life, widespread damage and economic loss and that in 2000 and 2001 almost 35 million people in Africa were affected by these disasters.

Furthermore, the International Strategy for Disaster Reduction (2008:4) predicts that drought will continue to be a major concern for many African communities. The frequency of weather and climate related disasters has increased since 1970 and the Sahel region and Southern Africa have become drier during the past three decades. Following this argument, in the future the African continent could face a reduction in water and this would impact on the agricultural sector. From an economic point of view, most countries affected by disasters have had their economic development severely interrupted. For example, the flood in Mozambique in 2000 displaced approximately 4,000 people in Maputo alone and destroyed the road network which linked the city with other provinces (Christie and Hanlon; 2001). The economic recovery took years to overcome. There is also the case of a volcanic eruption in 2002 at Mount Nyiragongo in Goma, in the eastern part of the Democratic Republic of Congo, which destroyed the tourist town of Goma. Another example is the droughts in Kenya and Ethiopia, which had a devastating effect on the agricultural production of these countries. There are many cases in the Sub-Saharan Africa the list is long.

\subsection{West Africa}

Adger and Brooks (2003: 27) argue that the Sahel drought of 1972 and 1973 was the culmination of a downward trend in rainfall that began in 1950, despite regionally high rainfall. By 1972, a large number of Sahelians had already suffered the effects of several years of drought. The only previous year in which the average rainfall for the entire region was similarly deficient was in 1913. Current information shows that the Sahel region is still experiencing floods, desertification and drought. It is also pointed out by World Health Organisation (WHO) (2004: 1) that the Sahel region continues to be affected by a range of natural disasters which have caused various health problems in the region.

For example, in 2004 there were a number of epidemic diseases which spread across West Africa such as cholera, yellow fever, meningitis, and HIV/AIDS. The WHO considers the proliferation of these diseases as a new configuration of hazards (UNDP: 2004). The reason is simply that these epidemics are decimating communities in Sub-Saharan African countries.

Furthermore, in 2001, Ghana experienced torrential rain, which caused widespread floods in the capital, Accra. More than 100,000 homes were destroyed. Roads in the city were under water; others were completely washed away (BBCNews: 2001). Moreover, Songsore et al (2008) maintain that floods in Ghana are more frequent in the rainy season but that flash flooding is prone to happen at any time. During the rainy season, between May/June and August, severe flooding of large areas of Accra has become a predictable seasonal occurence. This situation has arisen because the capital was built on a flat terrain, and its drainage system is currently inadequate.

In 2007 there was a similar situation in the neighbouring country of Nigeria where floods destroyed housing and other infrastructure, especially in poor areas. Disaster events were registered in nine federal states of Nigeria, namely Lagos, Ogun, Plateau, Sokoto, Nasarrawa, Bauchi, Yobe, Borno and Kebi. Other factors that contributed to the flood problem were poor drainage systems in those states and an overflow of water from a dam, which caused a major impact (Red Cross: 2007). 
The analysis presented by ENDA (2008: 198) shows that the West African region is associated with hazards such as drought, desertification, flood, spread of disease and various other hazards. These occur not only in West African countries but are also found in other parts of Sub-Saharan Africa. In addition, in 2004 and 2005, Mali, Niger and Senegal registered drought, all of which caused extensive economic loss.

Burkina Faso, like other countries of the West Africa sub-region faces similar hazards. According to the International Federation of Red Cross and Red Crescent Societies (2007: 1), in 2007 Burkina Faso registered one of its heaviest rainfalls, which caused havoc throughout the country. The government reported that over 40,000 people were severely affected and were forced to live in miserable conditions. Together with international organisations, the government intervened, but economic losses and damage to housing and other infrastructure was extensive. According to government sources in Burkina Faso, no less than 8,412 houses were damaged. It is unclear whether these houses were ever rebuilt. The observation is that West African countries are exposed to natural disasters virtually every year.

Another argument the paper suggested was that the growing incidence of hazards in the West Africa region could be linked to climate change. According to Nyong and Fiki (2005: 8) it is anticipated that climate variability and change in West Africa will have an overwhelming impact on agriculture and land use; the ecosystem and biodiversity; human settlements; diseases and health; hydrology and water resources. They suggest that the region should have a better mechanism in place to try to combat the effect of climate variability.

\subsection{Central Africa}

The countries of this region have also suffered similar hazards. Since 2006 the region has registered significant floods in most countries in Central Africa (Red Cross; 2008: 1). For example, according to Ayanji (2004: 4) in Cameroon the extensive and prolonged rainfall caused severe flooding in 2001. In the municipality of Limbe the heavy downpours destroyed not only large areas of agricultural land but also urban property and homes in the surrounding suburbs, especially dwellings inhabited by the poor. The floods thus had a direct and indirect impact on human, environmental, and economic losses.

The Republic of Congo experiences flooding virtually every year. According to the Red Cross Bulletin (2007: 1) Brazzaville, the capital city of Congo, registered torrential rain which caused flooding in the central city area in 2007. One reason for the flooding phenomenon is the situation of the city on the banks of the Congo River, the boundary between the Democratic Republic of Congo (DRC) and the Congo Republic. Another reason is the poor drainage in Brazzaville, which makes it very vulnerable to flooding.

The DRC is considered one of the countries most affected by floods. It is at the mercy of the Congo River, which crosses it from East to West. The flooding of the river presents a serious threat to riparian communities, including the 12 million inhabitants of Kinshasa, the capital. The water level of the Congo River has been increasing steadily. This is a threat that the DRC government needs to take very seriously because a combination of cholera (which is recurrent in the country) and floods would complicate the situation immeasurably (Red Cross Bulletin; 2007). Beside the flood situation in the western DRC, in the eastern part of the country there is also the danger of volcanic eruptions. 
According to the United Nations Disaster Assessment and Co-ordination (2008: 3) the East African rift valley system is one of the most seismically active regions on the African continent. The Lake Kivu basin is among the most active areas in this rift and earthquakes frequently damage villages and towns situated there. The earthquakes also generate landslides on mountain slopes and hills surrounding Lake Kivu. Seismic studies and field observations indicate that since 1997 the Lake Kivu basin has become more active than usual. In 2007 the country experienced another earthquake registering 6.1 on the Richter scale, which struck the province of Sud Kivu (UNDAC; 2008: 3). Significant damage was caused in Bukavu, the capital city of the province and in surrounding districts. Other countries of the central Africa region such as Gabon, Central African Republic and Săo Tomé and Principe also registered floods and landslides. According to the Red Cross Bulletin (2007: 2), flood is registered as a disaster when occurring annually in these countries.

\subsection{East Africa}

The eastern part of Africa is recognised as one of the regions which has suffered severe drought for a number of years. Countries well known as being at high risk of drought conditions include Kenya, Ethiopia and Sudan. The drought has had a particularly negative impact on the poor because of lack of food. According to CRED (2009: 4) climatological disasters in the form of drought have claimed many victims in the eastern part of Africa, with more than one third of the population affected in Eritrea, Djibouti, and Somalia. Then too, Kenya has suffered drought conditions for the past decade. In 2000, it experienced one of its worst droughts in 37 years. According to IFRC (2005) the Kenyan government needed international assistance in terms of food supplies for more than 2 million of its people.

It is argued by Gadain et al (2005: 165) that an impact analysis of the El Nino flood event clearly shows that the Kenyan government is inadequately prepared to mitigate the adverse effects of such disasters. The government has neither a flood disaster management policy nor an institutional framework to monitor and manage flood related disasters. Floods registerd a significant impact in the West Kenya region and destroyed crops over a wide area. The country also registered a high death toll at that time. In the wake of this disaster the Kenyan government decided to strengthen its disaster capacity, and placed a major focus on preparedness and risk management. In April 2009, the government realised that there was another severe drought in western Kenya where a pastoral community had lost many head of cattle and crops had failed. Most of the inhabitants of that part of Kenya needed government assistance.

Turning now to Ethiopia, according to the National Policy on Disaster Prevention and Management (1993: 2) this country is severely threatened by disasters induced by drought and other natural hazards. In the last 20 years, disasters have, in varying degrees, occurred every year. These have cost the Ethiopian government heavily in terms of both human lives and resources. The Ethiopian government is determined to take every possible precaution to eradicate these persistent droughts. This is why the government decided to draw up the National Policy on Disaster Prevention and Management.

The reality is that Ethiopia has faced drought conditions for decades. The areas worst hit have been on the border between Ethiopia-Djibouti, northern-Kenya, central and south Somalia and parts of Eritrea (Red Cross, 2006: 1). It is argued by UNDP (2004: 49) that Ethiopia shows high levels of vulnerability to drought and has recorded a growing number of droughts in the period 1980 to 2000 . 
The drought conditions in Ethiopia have a significant impact on food security in that country. It is argued by the International Red Cross Crescent (2006: 1) that as many as 11 million people are affected by drought in the wider Horn of Africa region. Food insecurity in Ethiopia has left almost 2.6 million people in need of emergency assistance. The worst hits are the pastoralist or agro-pastoralists in the southern and the southern east part of Ethiopia, where most communities are dependent on the fertility of the land. When there is a drought these people are forced to relocate to other areas where the land is relatively fertile. The cause of the drought in this region is a scarcity of rain. Ababe et al (2008: 2) argue that of those who are in immediate need of assistance, $69 \%$ reside in critically affected pastoral and agro-pastoral areas of the Afar region. Although the Ethiopian government has already established a policy on disaster prevention and management to deal with the problem of disasters, the reality is that the country still faces natural hazards every year. The impact of natural disasters as result of severe hazards drains the economy of the Ethiopian government. Ideally, the government should have a financial reserve to solve this problem.

The situation in Sudan is not substantially different from that in Ethiopia, which has faced drought and flood hazards for a long time. Sudan has registered drought for two decades. According to Telku, Braun and Zaki (1991: 16) Rainfall levels have declined in Sudan during the past three decades: mean annual rainfall declined by $6.7 \%$ between $1960-69$ and 1970-79, and by $17.7 \%$ between $1970-79$ and 1980-86. Drought has had severe consequences for the poor, and particularly those in the northern region of Sudan, many of whom faced hunger and even starvation. The low rainfall also had a negative effect on crop production, which dropped sharply.

The same authors argued that a $10 \%$ drop in annual rainfall resulted in a decrease of $7.3 \%$ and $3.0 \%$ in sorghum and millet production respectively. A marked drop in rainfall levels at the end of 1970 meant that drought conditions became even worse. Hulme (1984: 271) has shown that on the basis of observed rainfall data in the arid zone of Sudan, the years from 1979 to 1983 were as dry as the 1969-73 period. Following the same argument, the International Federation Red Cross Red Crescent (2001: 1) noted that severe drought was reported in the western and the central parts of Sudan which affected at least 900000 people, and that 600000 people were at risk of famine.

Sudan has also experienced severe flooding in past years. In 2007 the Sudanese government registered torrential rain across the country and the Nile and other rivers burst their banks in eight Sudanese states, resulting in widespread damage. According to an assessment of the situation by the government and to reports which appeared in the media, more than 30 people were killed, 100 were injured and more than 25000 houses were destroyed by the floods. Villages were submerged and the raging floodwaters caused extensive damage to infrastructure, including roads and bridges (IFRCRC, 2007: 1). The analysis provided in this article indicates that natural hazards still take place in virtually every country on the Africa continent. The relevant governments should be the main role player in attempts to offset these tragedies.

\subsection{Southern Africa}

Like its counterparts to the north, the Southern Africa region also faces the impact of natural hazards. In South Africa's Western Cape province wildfires occur annually and the threat of natural hazards is frequent in many other countries in the region. Research indicates that southern African countries have suffered at least two debilitating droughts, triggering serious water-related imbalances and causing loss of crops. The shortage of water also led to loss of livestock, wildfires, famine and outbreaks of disease. Furthermore, the consequence of drought in 
the 1994 and 1995 season caused a decline of cereal production by 35\% compared to the previous years (Southern Africa Environment Outlook: 2008). Similar circumstances were experienced in countries such as Malawi, Zambia and Zimbabwe.

Further, the region also registered floods. Some analysts have linked the impact of floods to climate change. It is argued by Singh (2006: 13), for example, that climate change has a direct impact on rainfall. Scientists forecast that in the coming years, countries in the Sahel region will receive increased rainfall and the threat of floods will increase while southern Africa is likely to encounter persistent drought.

In March 2000, flood caused by cyclone El Nino impacted heavily on the Southen Africa region, particularly in Mozambique, where more than 900 people were declared dead. As regards the threat of drought, Unganai (1994: 1) reports that droughts have become a regular occurrence in southern Africa and also one of the most debilitating natural disasters in the sub-region. In fact, it is becoming increasingly unusual for drought conditions not to be experienced somewhere in southern Africa each year. This hazard impacts most heavily on the region's agricultural sector, which plays a major role in the economics of the sub-region.

An analysis of statistics on droughts and floods in the Southern Africa region is presented below in the form of table. This is to illustrate that the entire region has registered severe natural hazards over an extended period of more than 150 years.

It suggests that most countries in the region have recorded natural disasters. Droughts and floods were the most frequent natural hazards. The table shows that virtually every year a natural hazard of some kind was registered. On the basis of this information it can be predicted that similar natural disasters will continue to occur in southern Africa. The consequences of these hazards obviously differ in each country, depending on the magnitude of the particular disaster.

Table: 1 Chronology of droughts and floods in southern Africa

\begin{tabular}{|l|l|}
\hline $\begin{array}{l}1820 \\
1830^{a}\end{array}-$ & This was a decade of severe drought throughout Africa. \\
\hline $\begin{array}{l}1844 \\
1849^{a}\end{array}-$ & Southern Africa experienced five consecutive drought years. \\
\hline $\begin{array}{l}1875 \\
1910^{a}\end{array}-$ & $\begin{array}{l}\text { There was a marked decrease in rainfall in southern Africa, and } 1910 \\
\text { experienced a severe drought. }\end{array}$ \\
\hline $\begin{array}{l}1921 \\
1930^{a}\end{array}-$ & There was a severe drought throughout southern Africa. \\
\hline 1930 & $-\begin{array}{l}\text { Southern Africa experienced dry periods alternating with wet seasons and in } \\
\text { some years the rains were very good. The 1946-47 seasons experienced a } \\
\text { severe drought. }\end{array}$ \\
\hline $1950^{a}$ & $\begin{array}{l}\text { This 6-year period was dry across the entire region. Some records show a } \\
\text { severe drought in 1967. The equatorial region (including the DRC) } \\
\text { experienced above-average rainfall. }\end{array}$ \\
\hline $1981-82$ & Severe drought in most parts of southern Africa. \\
\hline 1982 & Most of sub-tropical Africa experienced drought. \\
\hline 1983 & This year saw a particularly severe drought for the entire African continent. \\
\hline $1986-87$ & Drought conditions returned to the region. \\
\hline
\end{tabular}




\begin{tabular}{|l|l|}
\hline $1991-92$ & $\begin{array}{l}\text { Worst drought in living memory experienced in southern Africa, excluding } \\
\text { Namibia. }\end{array}$ \\
\hline $1994-95$ & $\begin{array}{l}\text { Many countries in the SADC were hit by a severe drought, surpassing the } \\
\text { impacts of the 1991 to } 1992 \text { drought in some regions. }\end{array}$ \\
\hline $1999-$ & $\begin{array}{l}\text { Cyclone Eline hit the region and widespread floods devastated large parts of } \\
\text { the Limpopo basin (southern and central Mozambique, southeastern } \\
\text { Mozambique, parts of South Africa and Botswana). }\end{array}$ \\
\hline $2000-$ & $\begin{array}{l}\text { Southern Africa experienced abnormally high rainfall and disastrous floods } \\
\text { causing damage to infrastructure, loss of life and property }\end{array}$ \\
\hline $2002^{\text {a }}$ & $\begin{array}{l}\text { Parts of southern Africa received heavy rains resulting in flooding causing } \\
\text { considerable structural damage, destroying schools, crops, telecommunications } \\
\text { and roads. }\end{array}$ \\
\hline $2006^{\mathrm{b}}$ & $\begin{array}{l}\text { Cyclone Favio hit Madagascar and Mozambique and affected parts of } \\
\text { Zimbabwe. Flooding killed about 40 people and affected more than 120,000 } \\
\text { people in Mozambique. Nearly 90,000 people had to be evacuated. More than } \\
700 \text { cases of disease were reported among flood victims. Parts of Angola, } \\
\text { Namibia and Zambia were also struck by devastating floods in early 2007. }\end{array}$ \\
\hline $\begin{array}{l}\text { Early season floods were recorded in Malawi, Mozambique, Tanzania, Zambia } \\
\text { and Zimbabwe, affecting more than 190,000 people by January 2008. }\end{array}$ \\
\hline $2008^{\text {d }}$
\end{tabular}

Source: Southern Africa Environment Outlook: 2008

\section{Statistical data analysis}

It is important to clarify that the available statistical data has been reorganised for the purposes of this article. These figures do not stipulate particulars of the specific disasters that occurred in each country in Africa for the past 30 years. Some countries experienced more natural disasters than others. Another important point that must be made is that this present analysis includes the North African countries. In its initial form, the disaster statistics from the Centre for Research on the Epidemiology of Disasters (CRED) at the University de Louvain in Belgium, only discussed disasters in sub-Saharan Africa. Figure 1 below presents a breakdown of the natural disasters that occurred in Africa for the 30-year period from 1974 to 2003.

Figure 1: Natural disasters in Africa: 1974 to 2003

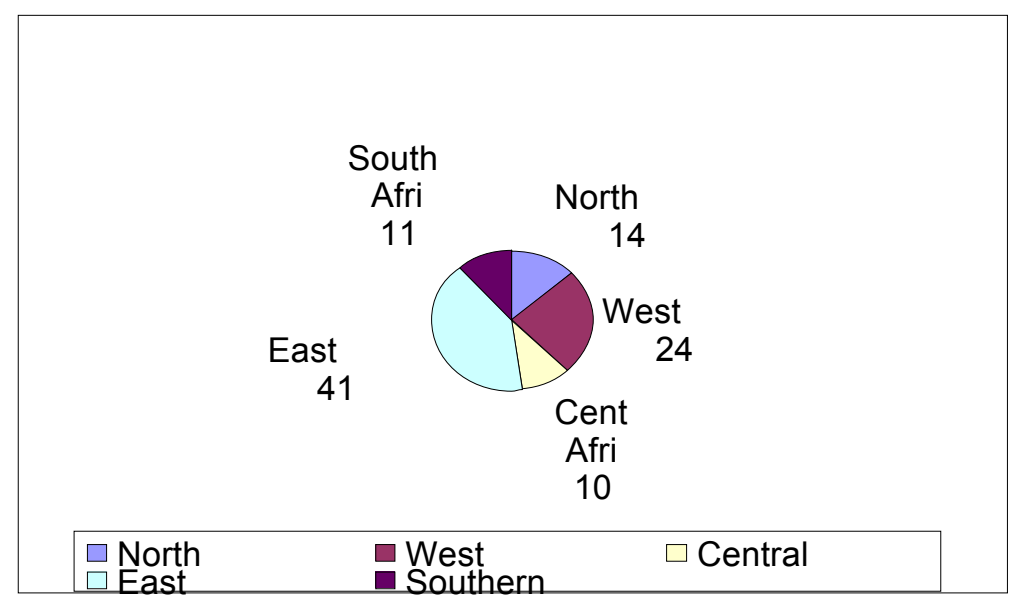

Source: CRED 
Figure 1 shows the spread (expressed as a percentage) of natural disasters in Africa for the past 30 years. The findings show that $41 \%$ of these disasters occurred in the East Africa region, while $24 \%$ were in the West Africa region. In the same 30-year period, $14 \%$ of natural disasters took place in the North Africa region. Southern Africa recorded only $11 \%$ of the continent's natural disasters, while the region with the lowest percentage, is central Africa with 10\%., although this region is not without risk of such disasters. Eastern African countries are by far the worst off in terms of the number of disasters registered on the continent. The data indicates that for the past 30 years, 379 natural disasters occurred in that part of Africa. By way of comparison, southern Africa registered 101 disasters. However, it is clear that each region on the continent faced a number of hydrometeorological hazards.

Figure 2 provides a graphic representation of the five regions showing the comparable geographic incidence of hydrometeorological disasters for the past 30 years.

Figure 2: Hydrometeorological disasters in Africa: 1974 to 2003

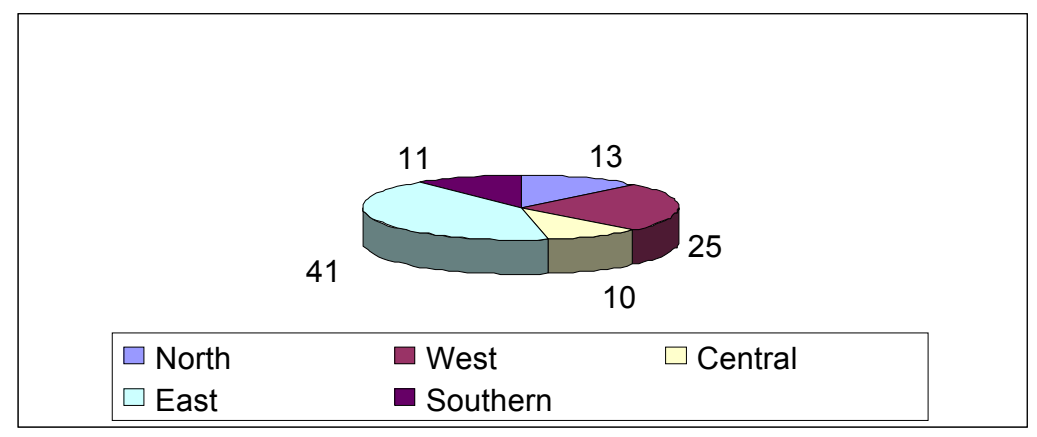

Source: CRED

According to Figure 2 above the readings for hydrometeorological disasters that occurred in the period 1974 to 2003 in eastern Africa, western Africa, northern Africa, southern Africa and central Africa are $41 \%, 25 \%, 13 \% 11 \%$ and $10 \%$ respectively.

The next figure (Figure 3) provides an indication of the geological disasters that took place on the African continent in the same 30 -year period.

Figure 3: Geological disasters in Africa: 1974 to 2003

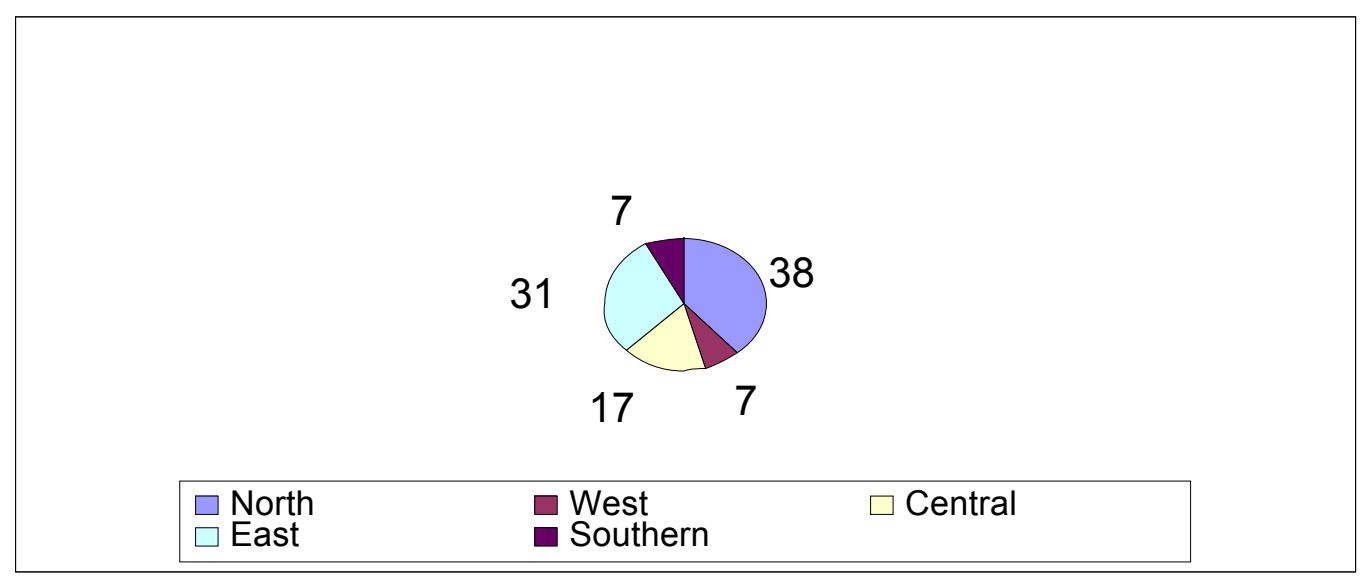

Source: CRED 
In Africa, geological disasters are less prevalent than other forms of natural disasters. The northern African countries are the most at risk with a reading of $38 \%$ as compared to $31 \%$ in eastern Africa and 17\% in central Africa. Western and southern Africa both recorded the same incidence (7\%) of the continent's geological disasters over the same 30-year period.

Figure 4: Drought hazards in Africa: 1974 to 2003

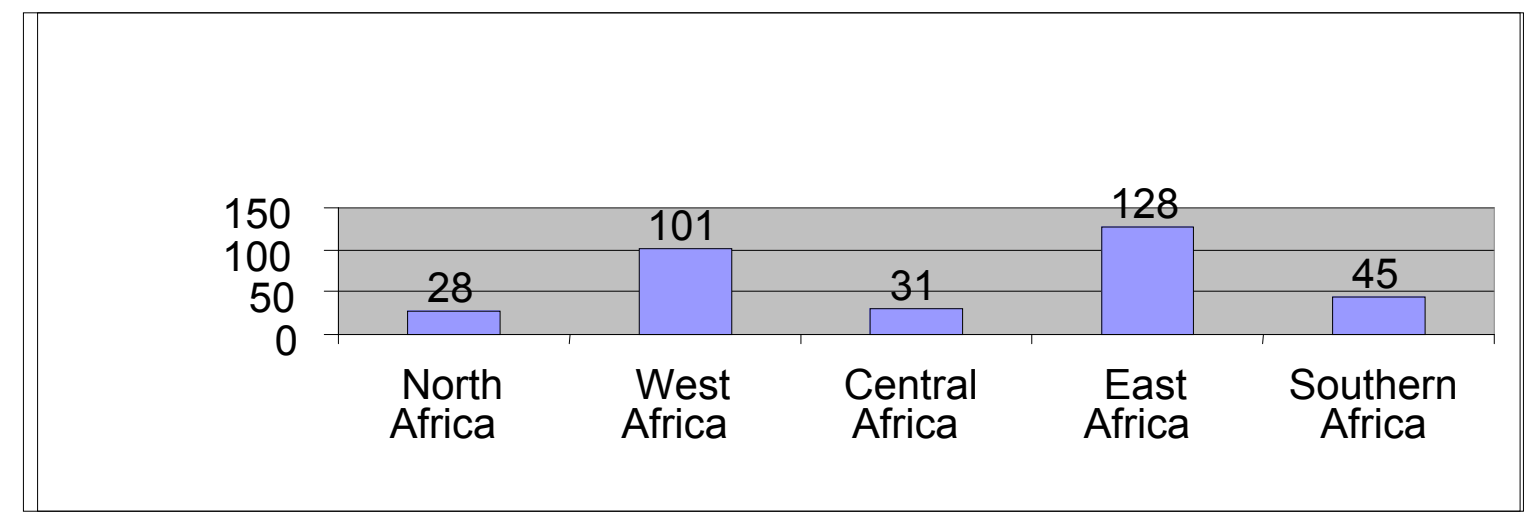

\section{Source: CRED}

Each region of the continent recorded a fairly high number of droughts in the 1974 to 2003 period. Reading from the left of Figure 4, and beginning with the North Africa region, 28 cases of drought were recorded. West Africa was considerably worse off with 101 cases while in central Africa there were 31 cases reported. The East Africa region was severely stricken by drought in the 30 years of statistical analysis and shows by far the highest incidence of this natural disaster. There were 128 cases of drought in that part of the continent. However, in the SADC region, the number dropped by more than half to 45 cases of drought for the same period.

Figure 5: Flood hazards in Africa: 1974 to 2003

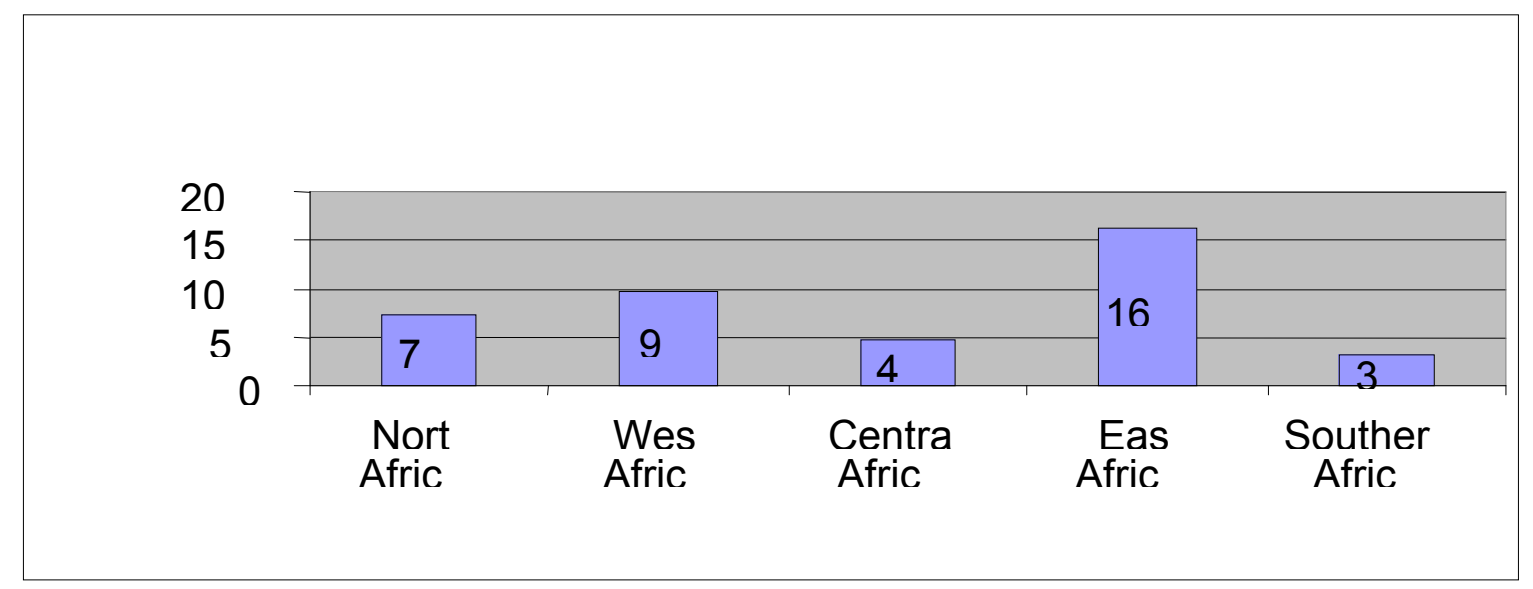

Source: CRED

The incidence of flooding increases every year on the African continent. The 30 years of data analysis in this research is aimed at presenting a clear picture of the current situation on the continent. The North Africa region experienced 74 floods in the evaluation period. This 
incidence of flooding continues until today. In western Africa the number of floods was far higher, reaching 98 cases, but in central Africa there were only 47 cases. By far the highest incidence of this hazard was in the eastern African countries where 162 cases were recorded in the past 30 years. In the SADC region only 31 cases of floods were experienced, making southern Africa the region least affected in comparison with the rest of Africa.

Figure 6: Volcanic related disasters in Africa: 1974 to 2003

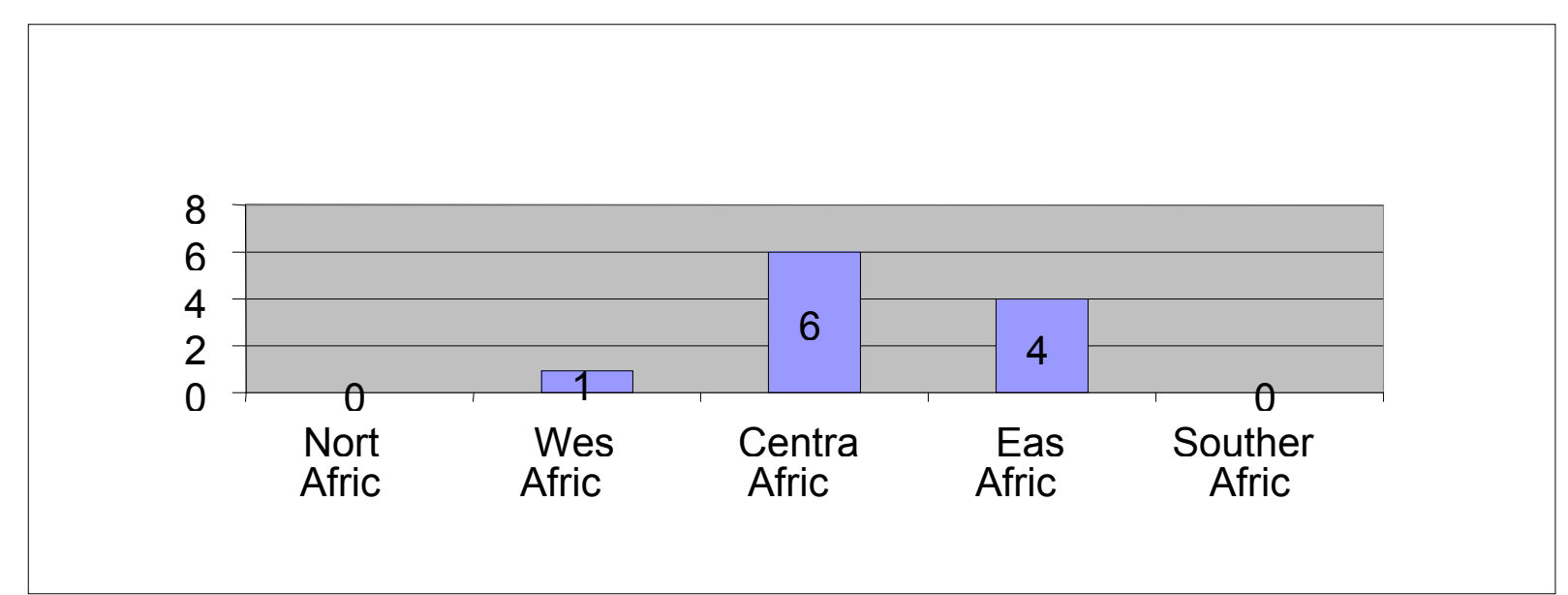

\section{Source: CRED}

Based on the available statistics, volcanic eruptions on the African continent are limited in number. Figure 6 demonstrates that there were no volcanic related disasters in northern Africa in the 30 years under review, while in western Africa only one case was recorded.

The number increased sixfold as far as the Central Africa region was concerned, the reason being that volcanic eruption is relatively common in the DRC and Cameroon (UNDAC: 2008). In eastern African countries only four cases of volcanic disasters occurred, while in southern Africa no volcanic eruptions were recorded in the survey period.

Figure 7: Disasters with economic damage in Africa: 1974 to 2003

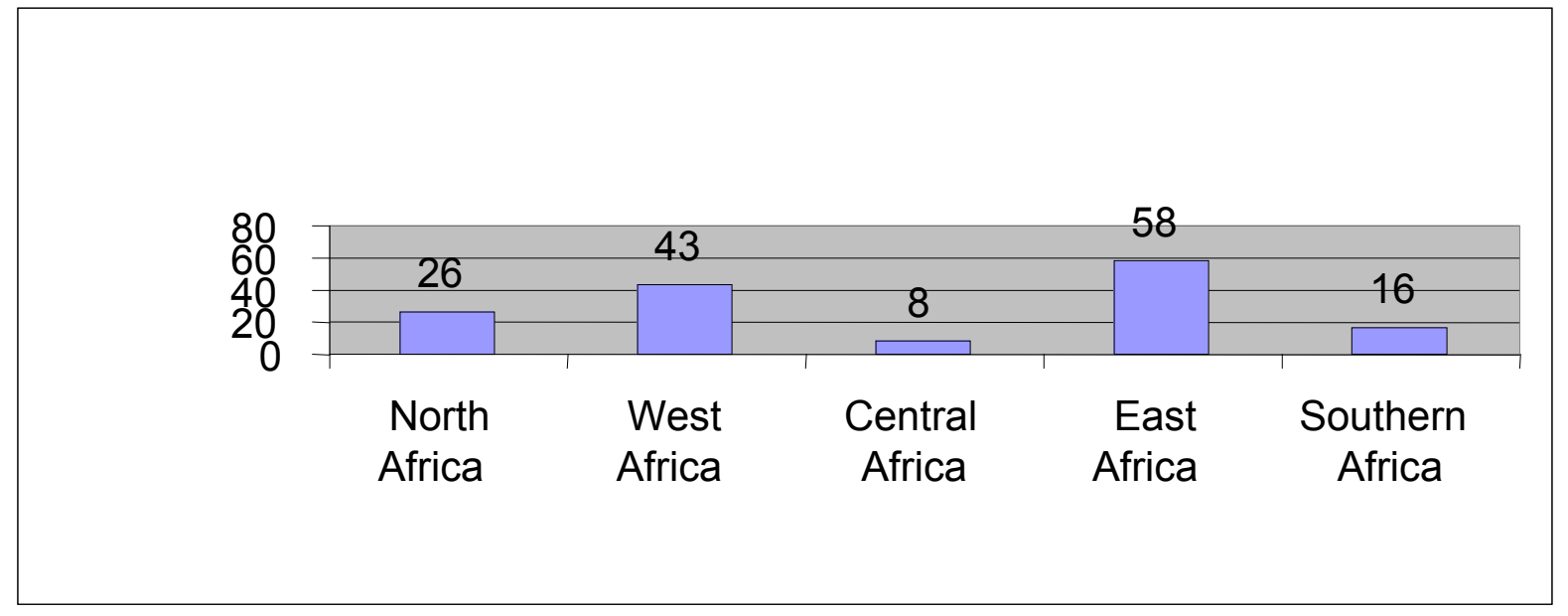

\section{Source: CRED}

The economic impact caused as a consequence of natural disasters in the period 1974 to 2003 differs from one African country to another. In the North Africa region 26 such cases were 
recorded. Figure 7 does not identify the specific countries, which were affected but it is clear that East Africa (58) is particularly vulnerable in this regard, followed by West Africa (43) North Africa (26) and southern African (16) cases. The Central Africa region recorded only 8 instances where natural disasters caused economic damage but this is linked to the limited number of natural disasters that occurred in the region.

\subsection{Key findings on statistical data}

The analysis presented in this data evaluation on natural disasters in Africa indicates that many countries on the continent faced economic losses. Some of these losses could not be recovered because of slow economic growth and other internal social and political issues within the countries concerned.

A crucial effect on the increase of hazards in various countries in Sub-Saharan Africa is climate change. This problem of disasters cannot be discussed without making reference to changes in climate. When analysing disaster events that took place in the last 30 years in different regions of the continent, there is a strong correlation between disaster and climate change. According, to ISDR (2008: 5) climate change affects disaster risk in two ways. Firstly because it increases weather and climate hazards, and secondly, because climate change increases the vulnerability of communities to natural hazards, particularly through eco-system degradation, reduction in water and food availability and changes in livelihoods.

In addition, Kreimer, Arnold and Carlin (2003: 12) argue that the economic losses suffered do serious damage to developing countries and those without post-disaster contingency plans; they are forced to divert funding from development to disaster relief, stunting their economic growth even more. They also claim that there are countries which do not even try to alleviate the risk of natural disasters, opting instead to demand that the international community bail them out.

The statistical analysis of available data for the 30-year period shows that the East African region of the continent is most heavily impacted by natural disasters. It is argued by United Nations for Environmental Programme (UNEP) (2008: 1) that the ENSO floods in 1998 in East Africa resulted in human suffering and death, as well as extensive damage to infrastructure and crops in Kenya. However, this analysis does not focus on Kenya, because the data shows that other countries in the region, such as Sudan, Ethiopia, Somalia, and Eretria to name but a few, also registered serious natural disasters during the same period.

Another region which recorded a high incidence of various types of natural disasters is western Africa. The literature shows that some of the countries in this part of the coninent, for example the Sahel region (Nigeria, Ghana, Burkina Faso, Mali and Benin) began to experience severe drought and other natural calamities such as lack of water resources, destruction of crops etc. before 1974. Furthermore, this situation has also caused the outbreak of various diseases in the region and natural disasters continue to impede development.

North Africa is a region that was not initially included in the research. When this study was first envisaged it focused on Sub-Saharan African countries. However, as the study progressed it became evident that while not as vulnerable as East Africa, North Africa is indeed at risk particularly as far as the total number (expressed as a percentage) of natural disasters is concerned (Figure 1, where it is the third higest reading); geological disasters (Figure 3); flooding (Figure 5); and economic loss (Figure 7). 
Southern Africa is in fourth position (of the five regions) in terms of overall percentage of natural disasters occurring in Africa over the 30 years covered by this survey. This needs to be explained. Some of the countries in the region faced devastating disasters, as did Mozambique in the floods of 2000. It was the only country in the SADC region that was hit by this disaster However, countries such as Malawi, Zimbabwe and Zambia experienced severe drought a few years earlier as shown in Table 1. The impact of these hazards led to severe economic loss, which in turn reflects on southern Africa's fourth standing (Figure 1) finding solutions in order to recover from such hazards is extremely difficult for many of these countries.

The Central Africa region faced the lowest percentage of natural disasters overall in the 30 years of statistical evaluation (see Figure 1). When compared with other regions on the continent. However, it recorded the highest number of volcanic eruptions, specifically in the Democratic Republic of Congo and Cameroon. The effects of this hazard in these two countries was (and remains so) exceptionally severe in terms of destruction of infrastructure and human suffering.

\subsection{The consequences of climate change}

The increased frequency of disasters in Africa is a consequence of climate change on the continent. According to CRED (2009: 16), in 2008 Africa registered a 20\% increase in global disaster events. The major type was climate induced disaster, most countries being affected by severe drought, which claimed more than 14 million victims. Following the analysis in this article it could be argued that in the long run many countries will be affected in terms of agricultural production. The ISDR (2008: 4) predicts that by 2020 agricultural yields in some African countries could be reduced by as much as $50 \%$. By 2080, areas of arid and semi-arid land in Africa might increase by $5-8 \%$.

Figures 4 and 5 indicate that the East African region tops the list in terms of natural disasters in Sub-Saharan Africa. This is closely linked to climate change in the region. Hulme et al (2001:4) claim that projection of climate change readings suggest that East Africa will experience warmer temperatures. They predict that by 2050 there will be a $5-20 \%$ increase in rainfall in the December to February season and a $5-10 \%$ decrease in rainfall from June to August. This situation will have significant consequences for water availability and drought conditions in that region.

These predicted climate changes and the variability of rainfall will impact heavily on the agricultural sector in East Africa because rain plays a major role in crop production. According to the International Food Policy Research Institute (IFPRI) (2004), agriculture contributes 40\% of the region's domestic product (GDP) and provides a livelihood for $80 \%$ of the population of East Africa. Increased occurrence of floods and drought is likely to decimate the agricultural sector in a number of countries in the region and famine will continue to wreak havoc.

The West Africa region ranks second highest in terms of disaster risk on the continent (see Figure 1). Again, this is linked to climate variability. It is argued by Madiodio et al (2004) that West Africa is highly vulnerable because some of its physical and socio-economic characteristics predispose it to be disproportionately affected by the adverse effect of climatic variations.

Moreover, the ISDR (2008) maintains that Africa is vulnerable to the effects of climate change because of multiple stresses and the continent's low adaptive capacity, arising from widespread poverty, and weak civil administration. These circumstances are also linked to conflict such as civil wars. All these issues impact negatively on the occurrence of natural disasters on the African continent and the ability to cope with them. 


\subsection{Government strategy to reduce disaster risk in Africa}

At this point the article suggests certain strategies to help African governments deal with natural disasters. This is especially relevant for those governments who are not as yet applying a mechanism to mitigate disaster. It has been pointed out that 30 years of statistics indicate that natural disasters occur in all regions of the continent so all country's face some risk. The paper suggests three points which every government should consider:

- Strong political governance;

- Internalisation of the responsibility; and,

- Specialist capabilities.

\subsection{Strong political governance}

It is recommended that governments should employ a skilled administrator on disaster risk management in all levels of government structures. This means senior public officials who have expertise in disaster risk reduction must be appointed to manage the disaster risk reduction department. According to UNDP (2004: 75) the heart of political governance implies participation, rule of law, transparency, responsiveness, consensus orientation, equity, effectiveness, efficiency, accountability and strategic vision as solutions for sustainable development and disaster risk reduction.

It is also argued by ISDR $(2008: 10)$ that government should develop a coordinated national mechanism. This should be implemented by calling an interdepartmental and national consultation forum with those involved in disaster risk reduction and climate change. What is required here is a government policy to be applied at different levels of government when disaster strikes. For example, in Tanzania, according to Robert et al (2009: 145) in order to minimise hazards in urban areas, in both formal and informal settlements, disaster risk reduction measures should be an integral part of the policies, law and planning procedures. Once institutionalised, these polices should be consistently enforced.

Furthermore, by political governance is meant that local community participation is essential in terms of intervention. Government should be able to take private participation into consideration.

\subsection{Internalisation of responsibilities}

African countries should be able show responsibility when natural disasters occur. Governments should offer strong intervention depending on the scale of the disaster. Some countries depend on external assistance from international non-governmental organisations in developed countries. The reason for internalised responsibility is to permit budgeting. A major problem is that some countries do not have the resources. In other words, a crisis budget may not be available.

Governments need to develop mechanisms to collect data relating to disasters to assist experts with a clear picture of the different hazards that threaten their particular country. This database would then be available to assist in terms of planning.

\subsection{Specialised capabilities}

Disaster risk reduction should become a ministerial function rather than simply a minor department as they exist in most African nations. In view of the increase of natural disasters on the continent it is each government's responsibility to put in place a specialised capacity particularly in central government and local administration. Mehrotra et al (2009: 11) explian 
that capacity here refers to the quality of institutions at various levels of government - local, regional, and national and within different departments. A lack of capacity impacts negatively when disasters occur.

\section{Conclusions}

This article demonstrates that natural disasters are on the increase in Africa and that governments must act; each region has recorded natural disasters of varying degrees and frequency. Research shows that climate-related disasters have increased by $20 \%$ in the period 2001-2008 on the continent. All African countries must therefore play their part by including disaster risk reduction as far as natural disasters are concerned.

The West Africa region has demonstrated for years that it is at very high risk indeed in this regard. It is one of the highest in terms of natural disasters registered in Sub-Saharan Africa. These natural hazards adversely affect a large number of poor communities and the damage in terms of economic loss runs into billions of dollars. But as yet, there is not an effective recovery plan; this is one of the biggest hurdles in that part of Africa.

The Central Africa region has recorded fewer disasters than other regions in Sub-Saharan Africa. The major difference is that here, disaster related to volcanic eruption has the highest incidence. Economic losses are also higher because of extensive devastation that volcanic disaster can bring.

The findings in this statistical analysis show the East Africa region is most severely affected in terms of natural disasters. Data proves that over the past 30 years most eastern African countries have been hard hit by these hazards.

Even today, natural hazards continue to cripple East Africa. There is currently a drought in Kenya that has led to the displacement of many communities. Moreover, other nations in the region face similar risks and other hazardous situations.

The Southern Africa region has experienced fewest natural disasters. In 2000 Mozambique was threatened by crippling floods and severe natural hazards have impacted on Zimbabwe, Zambia, Malawi, and South Africa. The agricultural sector, and thus food supply for the poorer populations, particularly those in the rural areas, was most affected.

Finally, the study demonstrates that natural disasters in Africa have a highly negative impact on the country concerned, seriously undermining sustainable development.

African countries should aim to mitigate such problems. Governments must insist that precautions be taken and sound management policies be implemented. This is vital to the development of the continent.

\section{References}

Ababe, D., Cultis, A., Aklilu, Y., Mekonnon, G., and Ghebrechirstos, Y. 2008.

Impact of a commercial destocking relief intervention in Moyale District, Southern Ethiopia. Overseas Development Institute. Published by Blackwell Publishing. 
Ayanji, E, N. 2004. A critical assessment of the natural disaster risk management framework in Cameroon. An end-of- course case study submitted to the department of city management and urban development of the World Bank Institute in partial fulfilment of the requirements of the award of a certificate in natural disaster risk management. Institute for Housing and Urban Development Studies (I.H.S,) Rotterdam.

Adger, W.N, and Brooks, N. 2003. Does global environmental change cause vulnerability? Natural disasters and development in a globalizing world. Published by Routledge. London.

Africa Union 2006. Report of the Africa Union Ministerial conference on disaster risk reduction. Africa Union. Addis Abeba.

Christie, F. and Hanlon, J. 2001. Mozambique and great flood of 2000. Indiana University Press, Bloomington, IN.

Centre for Research on the Epidemiology of Disaster (CRED) 2003. Thirty years of natural disaster 1974 to 2003: the numbers. University Catholique de Louvain. Presses Universitaires de Louvain. Bruxells

Centre for Research on the Epidemiology of Disaster 2009. Annual disaster Statistical review 2008. The numbers and trends. Universite Catholique de Louvain. Presses Universitaire de Louvain. Brexells

Ethiopia Government 1993. National Policy on Disaster Prevention and Management. Transitional Government of Ethiopia. Addis Abeba.

ENDA 2008. Disaster Risk Reduction in West and Central Africa. Local perspective. ENDA Tiers Monde. Dakar.

Gadain, H., Bidault, N., Stephen, L., Watkins, B., Dilley, M, and Mutunga, N. 2006. Reducing the impacts of floods through early warning and preparedness: A pilot study for Kenya. Natural disaster hotspots case studies. Disaster risk management series No 6. The World Bank Hazard Management Unit. Washington, D.C.

Global Disaster Risk 2007. Global Review. ISDR. United Nations. New York.

Homan, J. 2003. The social construction of natural disaster Egypt and UK. Natural disasters and development in a globalizing world. Published by Routledge Taylor and Francis Group. London and New York.

Hulme, M. 1984. “1983: An exceptionally dry year in central Sudan”. Weather 39, Page 270-274.

Huq, S., Kovats, S., Reid, H, and Satterthwaite, D. 2007. Editorial: Reducing risks to cities from disasters and climate change. Environment and urbanisation, Vol 19, No 1, Page 3 to page 15 .

International Strategy for Disaster Reduction (ISDRC). 2004. A global review of disaster reduction initiatives. Living with risk. Volume 1. United Nations. New York 
International Strategy for Disaster Reudction.2008. Climate Change and Disaster Risk Reduction. Briefing note No 1. United Nations, Geneva.

International Federation of Red Cross and Red Crescent Societies (IFRC) 2008. West and Central Africa: Flood preparedness. Focus on relief stock procurement and capacity building for response. Emergency appeal No MOR61003. Published by IFRC Geneva.

International Federation of Red Cross and Red Crescent Societies (IFRC) 2007. Congo Brazzaville: Floods and landslides: DREF bulletin No MDRCG001. Published by IFRC Geneva.

International Federation of Red Cross and Red Crescent Societies (IFRC) 2007.

Democratic Republic of the Congo: Floods in Kinshasa. DREF bulletin No MDRCD002. Published by IFRC Geneva.

International Federation of Red Cross and Red Crescent Societies (IFRC). 2007. West Africa: Floods focus on Burkina Faso. Published by IFRC Geneva. Ouagadougou.

International Federation of Red Cross and Red Crescent Societies (IFRC) 2007. Sudan: Floods. Emergency Appeal, Published by IFRC Geneva. Karthoum

International Federation of Red Cross and Red Crescent Societies (IFRC) 2001. Sudan: Drought. Information Bulletin No1. Published by IFRC Geneva. Karthoum.

International Federation of Red Cross and Red Crescent Societies (IFRC) 2006. Ethiopia: Drought. Emergency Appeal. Published by IFRC Geneva. Addis Abbeba

International Federation of Red Cross and Red Crescent Societies (IFRC) 2006. Ethiopia: Floods appeal No MORET 003. Published by IFRC Geneva.

International Federation of Red Cross and Red Crescent Societies (IFRC) 2007. Nigeria: Floods. Emergency Appeal. Published by Nigerian Red Cross Society. Lagos.

International Federation of Red Cross and Red Crescent Societies (IFRC) 2005. Kenya: Floods. Minor emergency. DREF bulletin No 05ME032. Published by IFRC Geneva.

International Food Policy Research Institute (IFPRI). 2004. Ending hunger in Africa: prospects for the small farmer, Washington, D.C., USA.

Kreimer, A., Arnold, M., and Carlin, A. 2003. Building Safer Cities. The future of disaster risk. Disaster risk Management series No 3. World Bank, Washington D.C.

Madiodio, N., Abel, A., and Abou, A. 2004. Reducing West Africa's vulnerability to climate impacts on water resources, wetlands and dessertitification. Published by the World Conservation Union. Gland, Switzerland. 
Mehrotra, S., Natenzon, C.E., Omojola, A., Folorunsh, R., Gilbride, J, and Rosenzweig, C. 2009. Framework for city climate risk assessment. Buenos Aaires, Delhi, Lagos, and New York. World Bank commissioned research. Marseille, France.

Nyong, A., and Fiki, C. 2005. Drought-related conflicts-management and resolution in the West African Sahel. Published by human security and climate change. An international workshop, Oslo, 21 to 23 June 2005.

Pelling, M. and Wisner, B. 2009. Disaster risk reduction cases from urban Africa. Published by Earthscan, London.

Robert B. K., John, L., Fred, L., Manoris, M., Benedict, M., Ally, N., and Emanuel, M. 2009. Building disaster-resilient communities: Dar es Salaam, Tanzania. Disaster risk reduction. Earthscan, London.

Singh, M. 2006. Identifying and assessing drought hazard and risk in Africa. Regional conference on insurance and reinsurance for natural catastrophe risk in Africa. Casablanca, Morocco, November 14/12/2005.

Songsore, J., Nabila, J. S., Yangyuoru, Y., Bosque-Hamilton, E, K., Amponsah, P. A., Alhassan, O. and Satterthwaite, D.2008. Envornmental Wealth Watch and Disaster Monitoring in the greather Accra Metropolitan, Ghana Universities press, Accra.

Southern Africa Environment Outlook 2008. A report by the Southern African Development and Partner: Southern African Research and Documentation Centre. Harare.

Teklu, T., Braun, J. V., Zakie, E. 1991. Drought and famine relationships in Sudan: Policy implication. Research reports 88. International Food Policy Research Institute. Khartoum.

Unganai, L, S. 1994. Drought and Southern Africa: A note from the Harare regional office. Drought Monitoring Centre. Harare.

United Nations Development Programme (UNDP) 2004. Reducing Disaster Risk. A challenge for Development. Bureau for Crisis Prevention and Recovery. United Nations Plaza. New York.

United Nations disaster assessment and Coordination (UNDAC) 2008. Democratic Republic of Congo Earthquake in the Great lakes region. 10 to 22 February 2008. UNDAC. New York.

United Nations Environmental Programme (UNEP) 2008. Global Environment Outlook. United Nations. New York.

World Health Organisation 2004. West Africa: Health sector needs assessment. WHO report. Geneva.

www.bbc.co.uk. 2001 June. Flood hit Accra causing 10 deaths and forcing 100,000 to flee their homes. Access date: 15/03/2009. 